Check for updates

Cite this: RSC Adv., 2017, 7, 27787

\title{
Synthesis of a poly(amidoxime-hydroxamic acid) cellulose derivative and its application in heavy metal ion removal $\uparrow$
}

\author{
Chenlu Jiao, ${ }^{a}$ Zhaofa Zhang, ${ }^{\mathrm{a}}$ Jin Tao, ${ }^{\mathrm{a}}$ Desuo Zhang, ${ }^{\text {ab }}$ Yuyue Chen (D) *a \\ and Hong Lin*a
}

Amidoxime and hydroxamic acid functional groups have comparable chelating ability with synthetic resins, but the synthesis of cellulose fibers bearing amidoxime and hydroxamic acid functional groups using simple and effective strategies have yet to be developed. In this study, a poly(amidoxime-hydroxamic acid) cellulose derivative (pAHA-cellulose) was prepared via free radical polymerization followed by an oximation reaction. A series of microscopic analyses and spectral tests proved that the pAHA-cellulose was covered with uniform amidoxime and hydroxamic acid functional groups. The use of pAHAcellulose towards heavy metal ion removal was investigated and an uptake equilibrium was achieved within $60 \mathrm{~min}$ for $\mathrm{Cu}^{2+}$ and $\mathrm{Zn}^{2+}$, and $120 \mathrm{~min}$ for $\mathrm{Pb}^{2+}$ and $\mathrm{Cr}^{3+}$, through a chelation mechanism. The adsorption behavior followed the pseudo-second-order kinetic model and Langmuir isotherm with Langmuir maximum adsorption capacities of 395.3, 333.3, 268.8 and $216.9 \mathrm{mg} \mathrm{g}^{-1}$ for $\mathrm{Cu}^{2+}, \mathrm{Pb}^{2+}, \mathrm{Cr}^{3+}$ and $\mathrm{Zn}^{2+}$, respectively. Regeneration of pAHA-cellulose did not significantly influence the adsorption towards metal ions for up to five sequential cycles. Considering the simple and efficient grafting process, excellent adsorbability and prominent renewability, pAHA-cellulose is believed to be a new and feasible candidate for heavy metal ion removal from aqueous solution.

Received 22nd March 2017 Accepted 12th May 2017

DOI: 10.1039/c7ra03365f

rsc.li/rsc-advances availability, eco-friendliness and biodegradability. Because of its renewable nature, cellulose can promote the cost-effective adsorbents for wastewater treatment. ${ }^{11-13}$ As seen its chemical structure, cellulose is a linear polysaccharide with long chains, which composed of a large amount of $\beta$ - $(1 \rightarrow 4)$-glycosidic linkages of D-glucose (Fig. 1a). ${ }^{14-16}$ In a repeating unit of a cellulose molecule, there are methylol groups $\left(-\mathrm{CH}_{2} \mathrm{OH}\right)$ at C-6 and hydroxyl groups $(-\mathrm{OH})$ at $\mathrm{C}-2$ and $\mathrm{C}-3$, and many attempts have been made to develop cellulose as a pollutant scavenger through functionalizing cellulose at C-2, 3 or $6 .{ }^{17-20}$

Polymeric ligands bearing amidoxime $\left(\mathrm{R}-\mathrm{C}\left(\mathrm{NH}_{2}\right)=\mathrm{N}-\mathrm{OH}\right)$ or hydroxamic acid $(\mathrm{R}-\mathrm{C}(=\mathrm{O})-\mathrm{NH}-\mathrm{OH})$ functional groups have long been of interest in removing metal ions from aquatic streams due to their comparable chelating ability with synthetic resins. ${ }^{17,21-23}$ Furthermore, amidoximated cellulose can act as a nanoreactor to produce nanocomposites with tailored characteristics. ${ }^{24,25}$ Also, amidoxime-reduced metal nanocomposites possess potent antimicrobial functionality. ${ }^{26}$ Recently, the team of Cui Yi reported an amidoximefunctionalized carbon electrode for uranium extraction from sea water. ${ }^{27}$ Dursun Saraydin et al. reported a poly(hydroxamic acid) hydrogel and its binding properties for uranyl ions. ${ }^{28}$ Typical approaches to produce cellulose derivatives containing hydroxamic acid and/or amidoxime groups can be summarized in several categories: (I) the grafting the unsaturated esters, acidic amides or acidic anhydrides to the
${ }^{a}$ National Engineering Laboratory for Modern Silk, College of Textile and Clothing Engineering, Soochow University, Suzhou 215123, P. R. China. E-mail: chenyy@ suda.edu.cn; linhong523@suda.edu.cn

${ }^{b}$ Nantong Textile \& Silk Industrial Technology Research Institute, Nantong 226004, P. R. China

$\dagger$ Electronic supplementary information (ESI) available: A comparison of the adsorption capacities between our poly(amidoxime-hydroxamic acid) cellulose derivative and representative adsorbents. See DOI: 10.1039/c7ra03365f 
(a)
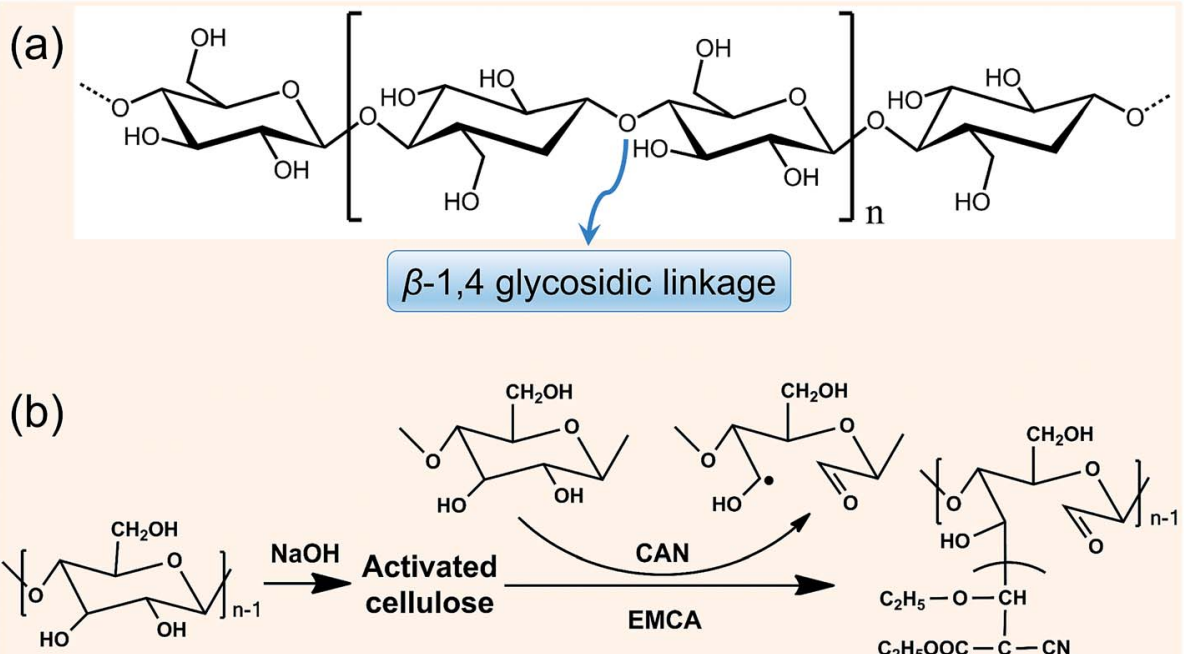

Raw cellulose $(\mathrm{RC})$
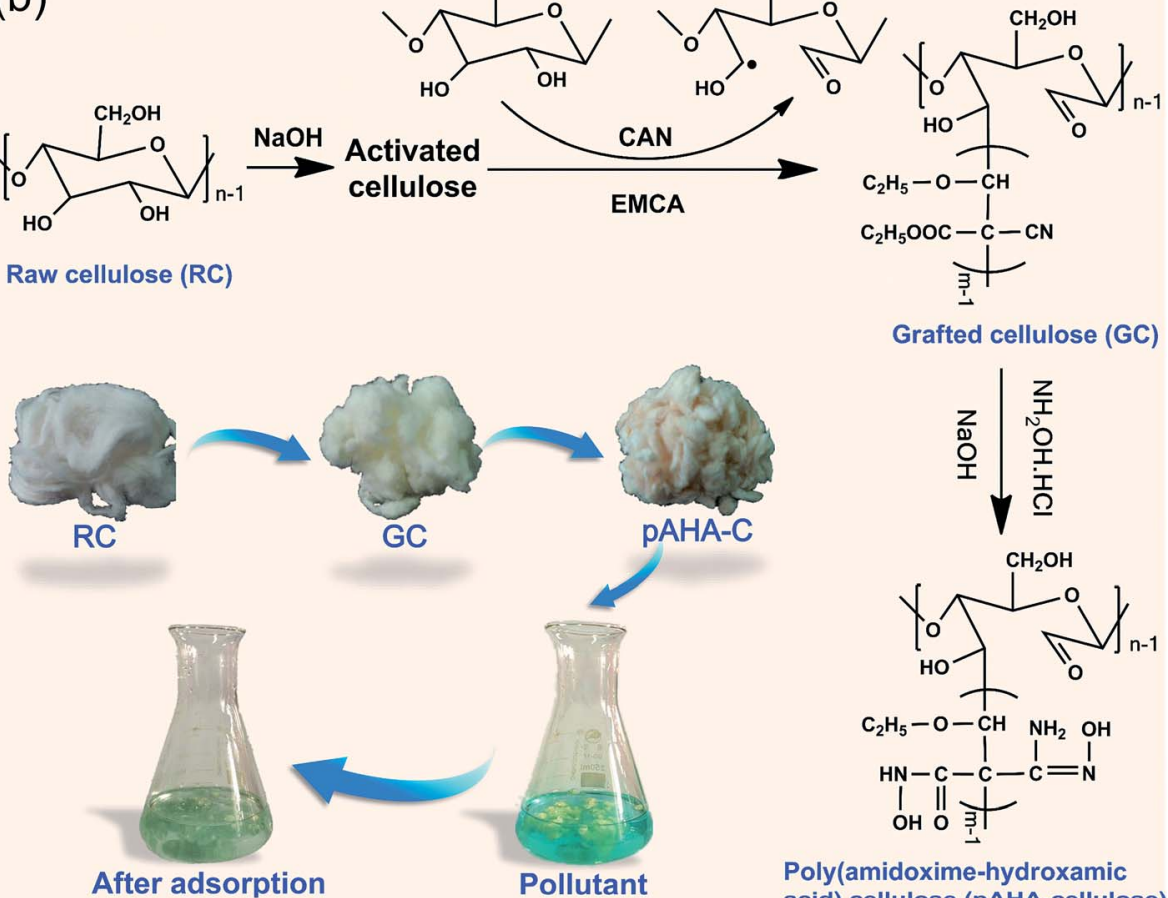

Poly(amidoxime-hydroxamic acid) cellulose ( $\mathrm{pAHA-cellulose)}$

Fig. 1 (a) The structure of cellulose and (b) the synthetic route used to prepare pAHA-cellulose and its adsorption process.

substrate (such as methyl acrylate, acrylamide and triflic anhydride), ${ }^{29-31}$ followed by oximation, (II) grafting acrylonitrile onto the support, ${ }^{32,33}$ followed by oximation and (III) direct oximation to cyan-containing materials (such as acrylonitrile fiber and cyanoethyl materials). ${ }^{34,35}$ To date, most reports have been centralized on the synthesis of cellulosic materials containing only amidoxime or hydroxamic acid functional groups. However, substrates with the co-existence of amidoxime and hydroxamic acid possess more activate sites and coordination sites, contributing to potentially higher adsorbability. Yong Wen et al. ${ }^{36}$ fabricated poly(hydroxamic acid)-poly(amidoxime) chelating cellulose ligands, however, two monomers of methyl acrylate and acrylonitrile were required to graft onto cellulose. Furthermore, some limitations such as various product structures and by-products were inevitably generated. Thus, is valuable to develop the synthesis of chelating cellulose fibers bearing amidoxime and hydroxamic acid functional groups using simple and effective strategies.

In this work, we have reported a new poly(amidoximehydroxamic acid) cellulose derivative (pAHA-cellulose) by grafting only one monomer. The resultant cellulosic ligand was characterized using a series of microscopic analyses and spectral techniques. The binding properties for heavy metal ions were investigated using batch adsorption experiments with respect to the $\mathrm{pH}$ value, initial concentration, contact time, adsorption kinetics, isotherms and regeneration ability.

\section{Experimental}

\section{Materials}

The cellulose fibers used in this work were cotton fibers, Yintong Cotton Co., Ltd (Suzhou, China). Ethyl(ethoxymethylene) cyanoacetate (EMCA) was purchased from Sigma-Aldrich (Shanghai, China) and used without further purification. Ammonium cerium nitrate (CAN), nitric acid $\left(\mathrm{HNO}_{3}\right)$, hydroxylamine hydrochloride $\left(\mathrm{NH}_{2} \mathrm{OH} \mathrm{HCl}\right)$, sodium hydroxide $(\mathrm{NaOH})$, hydrochloric acid (HCl), acetone, methanol, copper(II) nitrate hydrate $\left(\mathrm{Cu}\left(\mathrm{NO}_{3}\right)_{2} \cdot 3 \mathrm{H}_{2} \mathrm{O}\right)$, lead nitrate $\left(\mathrm{Pb}\left(\mathrm{NO}_{3}\right)_{2}\right)$, chromic nitrate nonahydrate $\left(\mathrm{Cr}\left(\mathrm{NO}_{3}\right)_{3} \cdot 9 \mathrm{H}_{2} \mathrm{O}\right)$ and zinc nitrate hexahydrate $\left(\mathrm{Zn}\left(\mathrm{NO}_{3}\right)_{2} \cdot 6 \mathrm{H}_{2} \mathrm{O}\right)$ were purchased from Sinopharm Chemical Reagent Co., Ltd (Shanghai, China). 

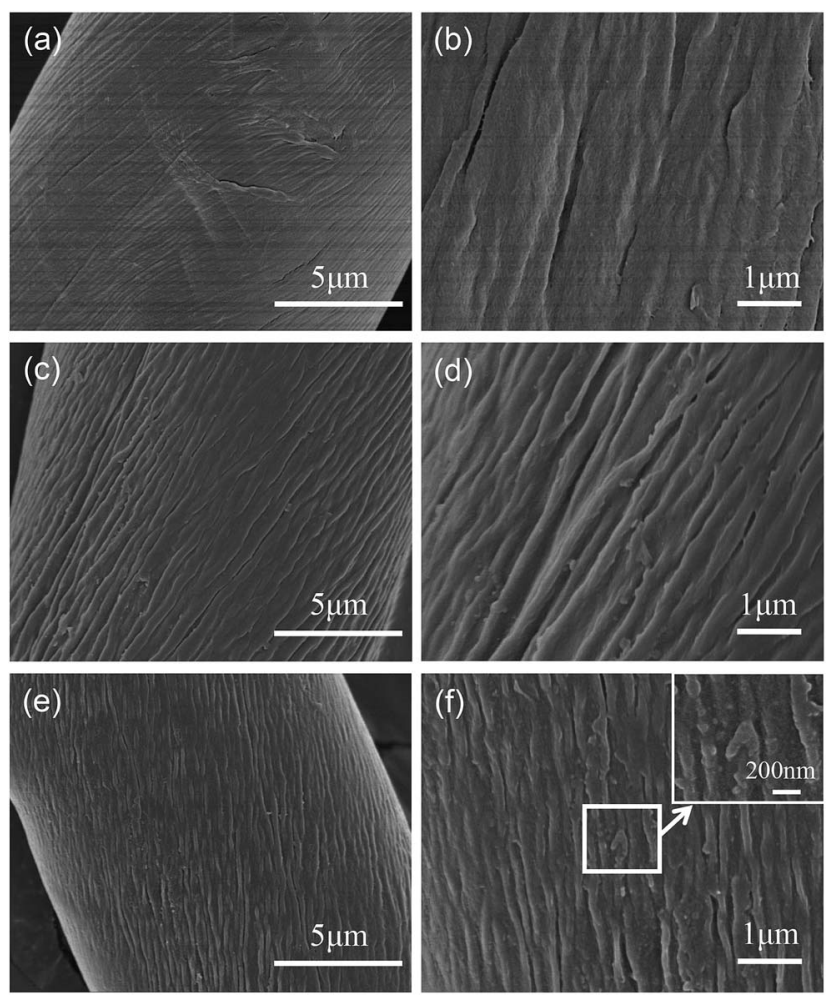

Fig. 2 SEM micrographs of ( $a$ and b) raw cellulose, (c and d) cellulose$g$-EMCA and (e and f) pAHA-cellulose.

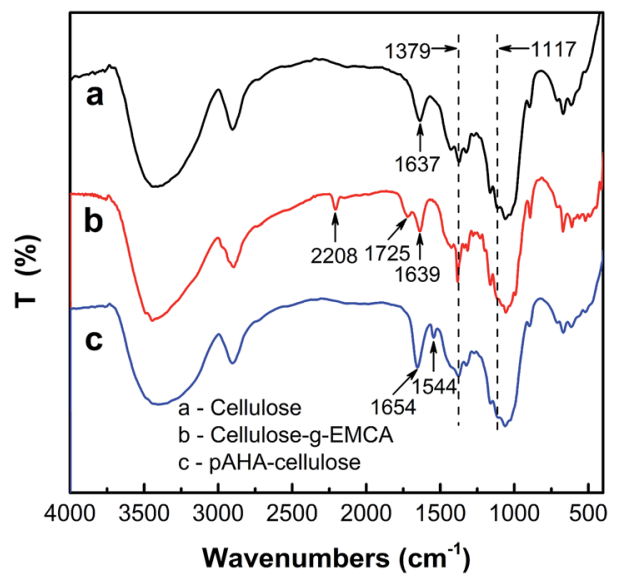

Fig. 3 The FTIR spectra of raw cellulose, cellulose-g-EMCA and pAHA-cellulose.

\section{Pretreatment of cellulose fibers}

Firstly, $5.0 \mathrm{~g}$ cellulose fibers were boiled in $250 \mathrm{~mL}$ of $\mathrm{NaOH}$ aqueous solution ( $2 \mathrm{wt} \%$ ) for $90 \mathrm{~min}$, then filtered and transferred into $150 \mathrm{~mL}$ of $\mathrm{NaOH}$ aqueous solution (18 wt\%). After stirring for $2 \mathrm{~h}$, the fibers were filtered again, washed several times with deionized water and dried at $60{ }^{\circ} \mathrm{C}$ for $3 \mathrm{~h}$ to obtain the activated cellulose fibers.

\section{Graft copolymerization procedure}

In a typical synthesis, $3.0 \mathrm{~g}$ of the crushed activated cellulose fibers (length $\leq 600 \mu \mathrm{m}$ ) and $100 \mathrm{~mL}$ of acetone were placed into a three-neck flask, which was equipped with a magnetic stirrer, condenser and $\mathrm{N}_{2}$ gas inlet. Subsequently, weighted CAN and 10 $\mathrm{mL}$ of $0.1 \mathrm{M} \mathrm{HNO}_{3}$ were added and allowed to react with the cellulose fibers at $50^{\circ} \mathrm{C}$ for $15 \mathrm{~min}$, followed by adding a certain amount of EMCA into the reaction system and kept stirring for $4 \mathrm{~h}$. Upon completion of the reaction, the cellulose- $g$-EMCA fibers were purified using a Soxhlet extractor with acetone for $24 \mathrm{~h}$. Then, they were washed several times with acetone and deionized water to remove the remaining reactants and dried at $60{ }^{\circ} \mathrm{C}$ to a constant weight. The percentage of grafting $\left(G_{\mathrm{p}}\right)$ was determined using eqn (1),

$$
G_{\mathrm{p}}=\frac{\left(W_{2}-W_{1}\right)}{W_{1}} \times 100 \%
$$

where $W_{1}$ and $W_{2}$ are the weights of original cellulose and cellulose- $g$-EMCA, respectively.

\section{Synthesis of pAHA-cellulose}

$2.47 \mathrm{~g}$ of $\mathrm{NH}_{2} \mathrm{OH} \mathrm{HCl}$ was dissolved into $60 \mathrm{~mL}$ of a mixed solution of methanol/water $(4: 1) .1 .42 \mathrm{~g}$ of $\mathrm{NaOH}$ was added to neutralize the $\mathrm{HCl}$ and the precipitated $\mathrm{NaCl}$ was removed by filtration. The $\mathrm{pH}$ of the aqueous medium was adjusted to 10 by adding $\mathrm{NaOH}$ solution and the hydroxylamine solution was maintained at a methanol-to-water ratio of $4: 1$.

The above prepared hydroxylamine solution was added into a flask containing $2.0 \mathrm{~g}$ of cellulose- $g$-EMCA $\left(G_{\mathrm{p}}=37 \%\right)$ and the oximation reaction was executed at $70{ }^{\circ} \mathrm{C}$ for $4 \mathrm{~h}$ using a condenser. After completion of the reaction, the fibers were filtered and washed several times with a methanolic solution (methanol: water $=4: 1$ ). Then, the cellulose fibers were treated with $0.1 \mathrm{M} \mathrm{HCl}$ in methanolic solution for $10 \mathrm{~min}$. Finally, the product was filtered and washed several times using distilled water, and dried at $60{ }^{\circ} \mathrm{C}$ to a constant weight to obtain the pAHA-cellulose.

\section{Characterization}

The morphology of cellulose fibers was studied using field emission scanning electron microscopy (FE-SEM, S-4800, Hitachi, Japan). Fourier transform infrared spectroscopy (FTIR, Nicolet 5700, Thermo Nicolet, USA) was performed to observe the chemical groups. Surface chemistry analysis was performed using X-ray photoelectron spectroscopy (XPS, Axis Ultra HAS, Shimadzu, Japan). X-ray diffraction studies were performed on an X-ray diffractometer (XRD, Bruker AXS, D8 Advance, Germany). The concentrations of metal ions were tested by inductively coupled plasma atomic emission spectroscopy (ICP-AES, iCAP 6000 DUO, Thermo Scientific, USA).

\section{The adsorption and desorption study of pAHA-cellulose}

$0.1 \mathrm{~g}$ of pAHA-cellulose was soaked into $100 \mathrm{~mL}$ of a metal ion solution and the adsorption process was carried out at $30{ }^{\circ} \mathrm{C}$ with stirring. The adsorption capacity was calculated according to eqn (2),

$$
Q_{t}=\frac{\left(C_{\mathrm{o}}-C_{t}\right) V}{m}
$$



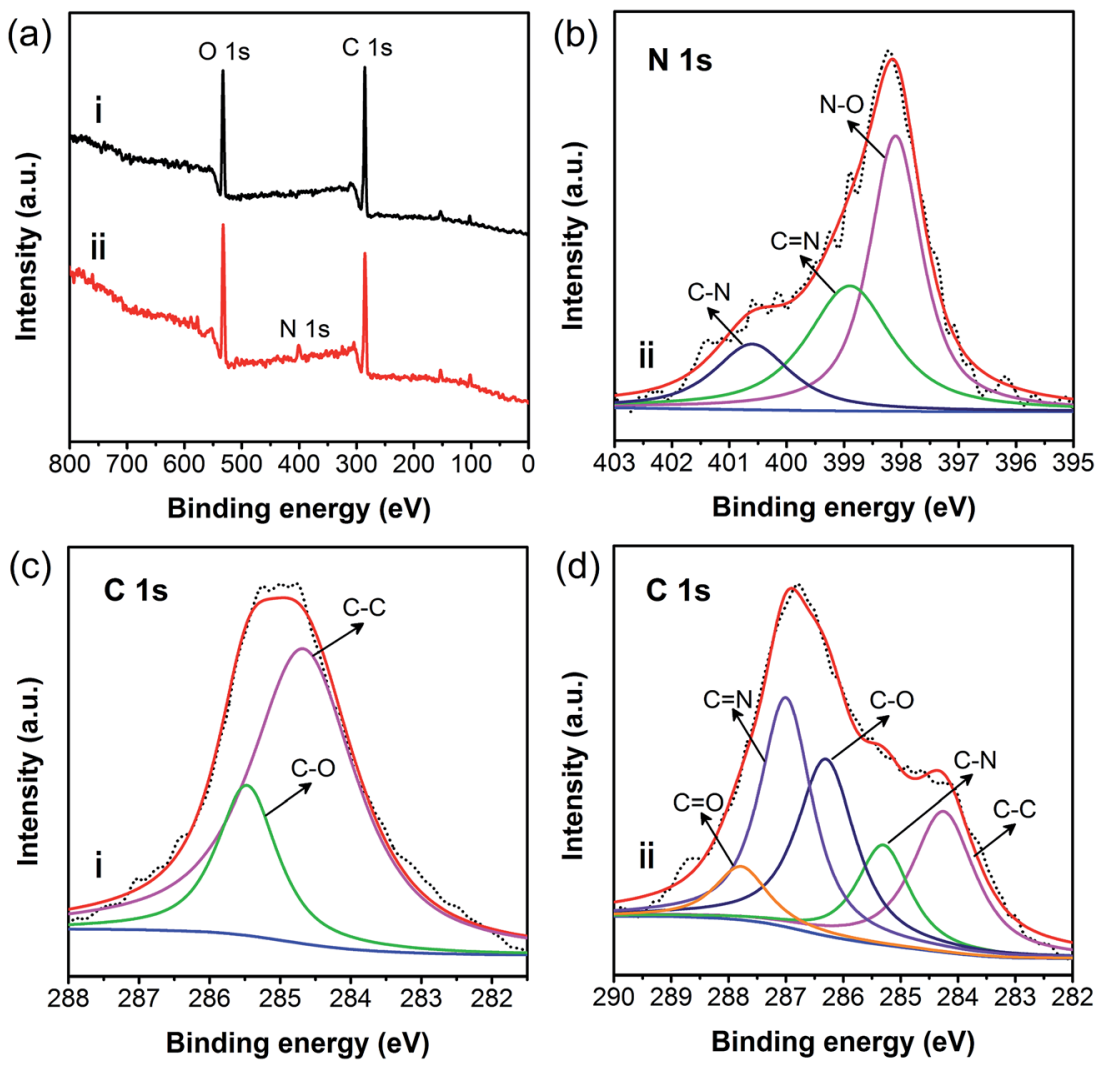

Fig. 4 (a) The XPS survey spectra of (i) raw cellulose and (ii) pAHA-cellulose. (b) The N 1s spectrum of pAHA-cellulose. (c) The C 1s spectrum of raw cellulose. (d) The $\mathrm{C}$ 1s spectrum of pAHA-cellulose.

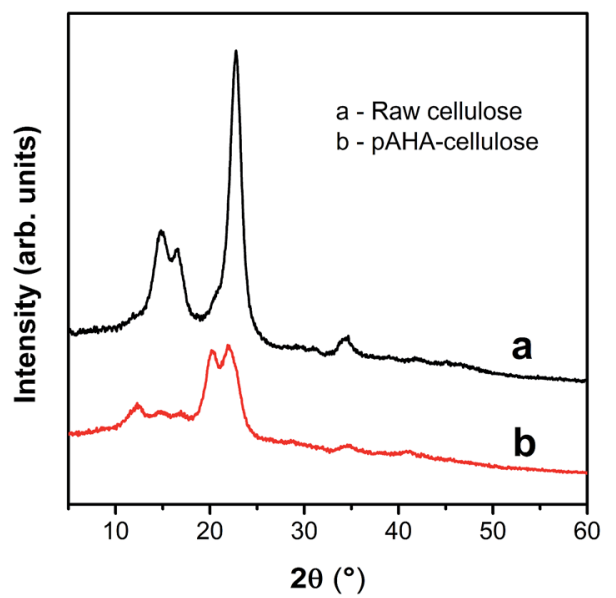

Fig. 5 The XRD patterns of (a) raw cellulose and (b) pAHA-cellulose.

where $C_{\mathrm{o}}\left(\mathrm{mg} \mathrm{L}^{-1}\right)$ and $C_{t}\left(\mathrm{mg} \mathrm{L}^{-1}\right)$ are the initial concentration and the concentration at a given time $t(\mathrm{~min}), Q_{t}\left(\mathrm{mg} \mathrm{g}^{-1}\right)$ is the adsorbed amount at time $t(\mathrm{~min}), V(\mathrm{~L})$ denotes the volume of solution and $m(\mathrm{~g})$ represents the mass of the adsorbent.

To evaluate the regeneration and reusability, the pAHAcellulose was adsorbed and desorbed repeatedly for five consecutive cycles. The desorption process was performed in $0.05 \mathrm{M} \mathrm{HCl}$ at $30{ }^{\circ} \mathrm{C}$ with stirring for $4 \mathrm{~h}$. After the elution course, the pAHA-cellulose was filtered and washed with deionized water, then dried at $60{ }^{\circ} \mathrm{C}$ to obtain the regenerated pAHA-cellulose.

\section{Results and discussion}

The principle and strategy for the synthesis of pAHA-cellulose

The mechanism of grafting on cellulose with vinyl or acrylic monomers has been studied for many years. ${ }^{17,19,37,38}$ In this study, cotton cellulose was grafted with EMCA via a free-radical initiation method, which involved CAN as an initiator (Fig. 1b). In the initiation step, the ceric ions $\left(\mathrm{Ce}^{4+}\right)$ formed a complex with the glucose units in the cotton cellulose and the hydrogen atoms were oxidized accompanied by the reduction of $\mathrm{Ce}^{4+}$ to $\mathrm{Ce}^{3+}$. It followed that bond cleavage occurred on the glycol group of cellulose at the $\mathrm{C}_{2}-\mathrm{C}_{3}$ position, generating keto-alcohol free radicals. ${ }^{15}$ Then, these cellulosic free radicals could initiate grafting with the EMCA monomer containing double bond and gave rise to the propagation reaction to form cellulose-g-EMCA. Subsequently, upon the addition of a hydroxylamine solution, the oximation reaction occurred for the conversion of cyan to the amidoxime group and acrylate to the hydroxamic acid group.

\section{The microstructure of pAHA-cellulose}

As shown in Fig. 2, distinct changes in the surface morphology of the cellulose fibers can be observed. The raw cellulose shows 


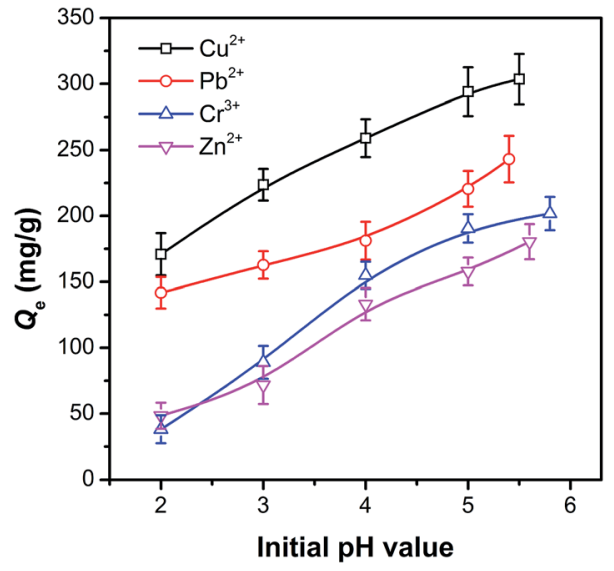

Fig. 6 The uptake of $\mathrm{Cu}^{2+}, \mathrm{Pb}^{2+}, \mathrm{Cr}^{3+}$ and $\mathrm{Zn}^{2+}$ on $\mathrm{pAHA}$-cellulose at various $\mathrm{pH}$ values (adsorption conditions: $500 \mathrm{mg} \mathrm{L}^{-1}, 30^{\circ} \mathrm{C}$ and $4 \mathrm{~h}$ ).

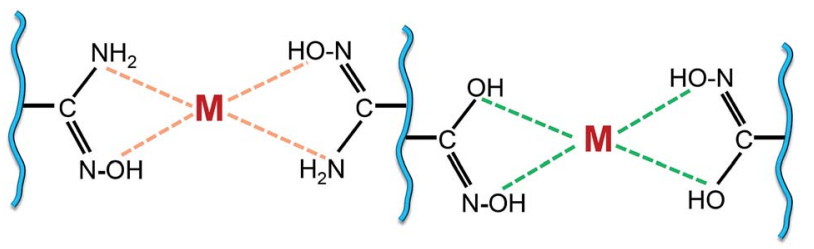

$\approx$ : pAHA-cellulose fibers $\quad \mathbf{M}$ : Metal ions

Fig. 7 A possible binding mechanism between pAHA-cellulose and metal ions.

a basically smooth texture and natural twists on the fiber's surface (Fig. 2a and b). After graft co-polymerization, the natural twists of cellulose- $g$-EMCA were etched and the grafted polymer was embedded in the grooves formed by adjacent natural twists of the cellulose fibers (Fig. 2c and d). While for pAHA-cellulose, the polymer coating can be clearly seen on the fiber's surface (Fig. 2e and f). When compared with natural cellulose, the pAHAcellulose surface becomes rough, which increases the specific surface area and is in favor of the attachment of pollutants.

\section{Chemical analysis of pAHA-cellulose}

The FTIR spectra of raw cellulose, cellulose- $g$-EMCA and pAHAcellulose are presented in Fig. 3. The characteristic adsorption peaks of raw cellulose (curve a) at 1637 and $1379 \mathrm{~cm}^{-1}$ can be attributed to the bending modes of $\mathrm{O}-\mathrm{H}$, methyl and methylene groups, respectively. ${ }^{34}$ After grafting, two new bands at 2208 and $1725 \mathrm{~cm}^{-1}$ appeared (curve b), which can be ascribed to the $\mathrm{C} \equiv \mathrm{N}$ stretching vibration of cyan and $\mathrm{C}=\mathrm{O}$ stretching of acrylate. Furthermore, the peak for methyl and methylene (1379 $\mathrm{cm}^{-1}$ ) increases dramatically, indicating the successful graft of EMCA onto cellulose. As for pAHA-cellulose (curve c), the cyan and acrylate bands disappear, and new adsorption bands form at 1654,1544 and $1117 \mathrm{~cm}^{-1}$ for the $\mathrm{C}=\mathrm{O} / \mathrm{C}=\mathrm{N}, \mathrm{N}-\mathrm{H}$ and $\mathrm{N}-\mathrm{O}$ stretching modes, respectively. ${ }^{36}$ These results confirm the conversion of cyan $(\mathrm{C} \equiv \mathrm{N})$ to amidoxime and the acrylate $(\mathrm{C}=\mathrm{O})$ to hydroxamic acid, demonstrating the successful synthesis of poly(amidoxime-hydroxamic acid) (pAHA)-functionalized cellulose.

In order to further confirm the chemical structure, XPS analysis was carried out as shown in Fig. 4. When compared with native cellulose (i), a new peak for $\mathrm{N}$ 1s was found in the pAHA-cellulose (ii) spectrum, as shown in Fig. 4a. Further analysis of $\mathrm{N} 1 \mathrm{~s}$ was carried out in Fig. $4 \mathrm{~b}$ and three peaks at 398.1, 398.9 and $400.63 \mathrm{eV}$ can be observed, indicating the introduction of $\mathrm{N}-\mathrm{O}, \mathrm{C}=\mathrm{N}$ and $\mathrm{C}-\mathrm{N}$ groups. ${ }^{39}$ As for the $\mathrm{C} 1 \mathrm{~s}$ spectrum of virgin cellulose, there are two peaks at 284.7 and $285.5 \mathrm{eV}$ in Fig. 4c, which can be attributed to $\mathrm{C}-\mathrm{C}$ and $\mathrm{C}-\mathrm{O}$ moieties. While for pAHA-cellulose (Fig. 4d), three new peaks corresponding to $\mathrm{C}-\mathrm{N}, \mathrm{C}=\mathrm{N}$ and $\mathrm{C}=\mathrm{O}$ groups are introduced, which is consistent with the $\mathrm{N}$ 1s region. In short, these results demonstrate the co-existence of the amidoxime and hydroxamic acid functional groups.

\section{XRD analysis of pAHA-cellulose}

In order to further determine the change in crystallinity, the XRD patterns of native cellulose and pAHA-cellulose were conducted in Fig. 5. There is a strong peak at $2 \theta$ of $22.76^{\circ}$ and three other peaks at $2 \theta$ of $14.80^{\circ}, 16.64^{\circ}$ and $34.40^{\circ}$ in native cellulose, indicating the characteristic cellulose I crystal structure. After
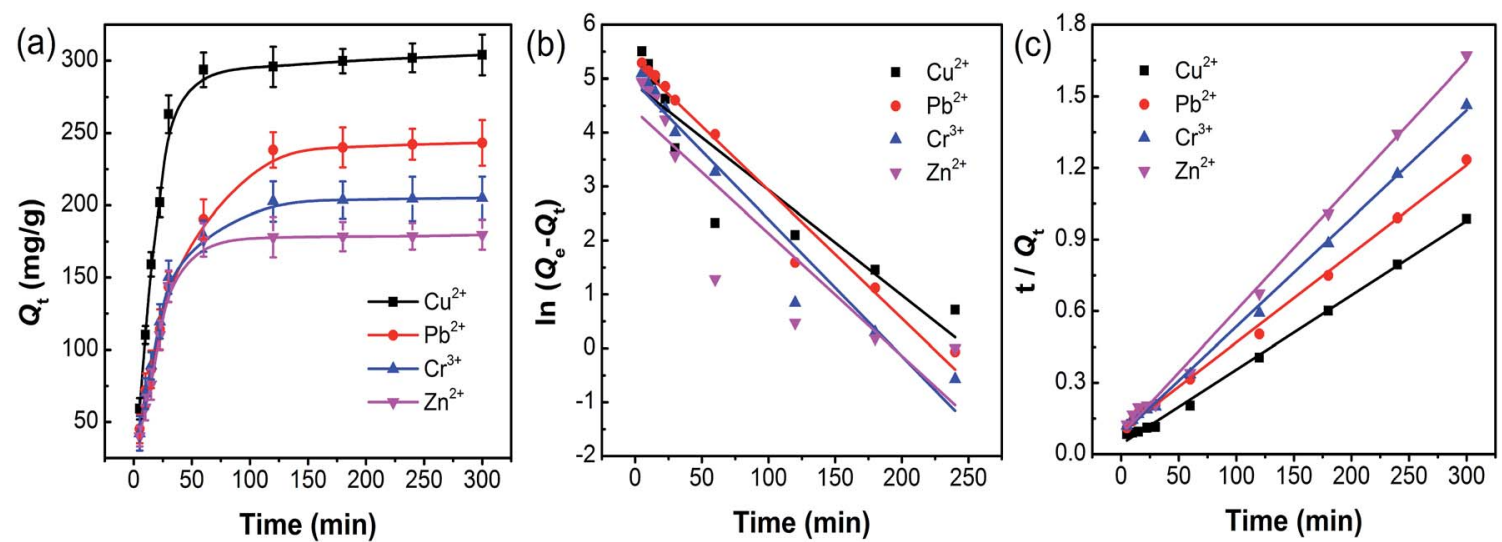

Fig. 8 (a) The adsorption behavior of pAHA-cellulose for $\mathrm{Cu}^{2+}, \mathrm{Pb}^{2+}, \mathrm{Cr}^{3+}$ and $\mathrm{Zn}^{2+}$, the (b) pseudo-first-order and (c) pseudo-second-order kinetic plots of $\mathrm{pAHA}$-cellulose for $\mathrm{Cu}^{2+}, \mathrm{Pb}^{2+}, \mathrm{Cr}^{3+}$ and $\mathrm{Zn}^{2+}$ (adsorption conditions: $500 \mathrm{mg} \mathrm{L}^{-1}, 30{ }^{\circ} \mathrm{C}$ and initial $\mathrm{pH}$ values). 
Table 1 The kinetic parameters obtained for the adsorption of $\mathrm{Cu}^{2+}, \mathrm{Pb}^{2+}, \mathrm{Cr}^{3+}$ and $\mathrm{Zn}^{2+}$ by pAHA-cellulose

\begin{tabular}{|c|c|c|c|c|c|c|c|}
\hline Adsorbate & $Q_{\exp }\left(\mathrm{mg} \mathrm{g}^{-1}\right)$ & \multicolumn{3}{|c|}{ Pseudo-first-order model } & \multicolumn{3}{|c|}{ Pseudo-second-order model } \\
\hline $\mathrm{Pb}^{2+}$ & 243.1 & 201.9 & 0.0238 & 0.9693 & 269.5 & 1.4133 & 0.9976 \\
\hline $\mathrm{Cr}^{3+}$ & 205.0 & 138.1 & 0.0254 & 0.9510 & 220.3 & 2.5434 & 0.9983 \\
\hline $\mathrm{Zn}^{2+}$ & 179.6 & 81.6 & 0.0227 & 0.7849 & 191.6 & 3.3673 & 0.9966 \\
\hline
\end{tabular}

oximation, two additional diffraction peaks appear at $2 \theta$ of $12.48^{\circ}$ and $20.24^{\circ}$, which are assigned to cellulose II. This conversion of crystal texture can be attributed to the activation treatment of the cellulose fibers..$^{15}$ Furthermore, the intensity of the diffraction peaks weakens remarkably, suggesting the partial destruction of the crystallinity in the fibers. This result is in line with the SEM results, confirming that the oximation reaction generates a rough microscopic structure, which will be conducive to the adsorption process.

\section{The effect of $\mathrm{pH}$ on adsorption}

The effect of $\mathrm{pH}$ on the adsorbability of pAHA-cellulose was investigated and the results shown in Fig. 6. A pH range of 2initial values was regulated with a sodium acetate buffer solution and the initial $\mathrm{pH}$ values for $\mathrm{Cu}^{2+}, \mathrm{Pb}^{2+}, \mathrm{Cr}^{3+}$ and $\mathrm{Zn}^{2+}$ were 5.5, 5.4, 5.8 and 5.6, respectively. The adsorption capacities for all the studied metal ions are observed to increase upon increasing the $\mathrm{pH}$ and reached a maximum adsorption capacity of 303.6, 243.1, 201.8 and $180.4 \mathrm{mg} \mathrm{g}^{-1}$ for $\mathrm{Cu}^{2+}, \mathrm{Pb}^{2+}, \mathrm{Cr}^{3+}$ and $\mathrm{Zn}^{2+}$ at their initial $\mathrm{pH}$ environments, respectively. This phenomenon indicates that the adsorption ability of pAHAcellulose was pH-dependent and its adsorption affinity towards the metal ions studied was in the following order: $\mathrm{Cu}^{2+}$ $>\mathrm{Pb}^{2+}>\mathrm{Cr}^{3+}>\mathrm{Zn}^{2+}$.

A possible chelation mechanism between pAHA-cellulose and the metal ions is illustrated in Fig. 7. It has been confirmed that pAHA-cellulose possesses amidoxime and hydroxamic acid functional groups. Therefore, when compared with those adsorbents containing only amidoxime or hydroxamic acid groups, pAHA-cellulose possesses more ligands and coordination sites. It can trap more metal ions and then form stable coordination compounds, ${ }^{21,32,33,40}$ providing a possibility of improving the adsorption capacity.

\section{Adsorption kinetics}

The effect of contact time on the adsorption capacity was evaluated in this study. As shown in Fig. 8a, an equilibrium can be reached at $60 \mathrm{~min}$ for $\mathrm{Cu}^{2+}$ and $\mathrm{Zn}^{2+}$, and $120 \mathrm{~min}$ for $\mathrm{Pb}^{2+}$ and $\mathrm{Cr}^{3+}$, respectively. In order to describe the pollutant uptake rate during the adsorption process, the experimental data obtained from adsorption behavior was analyzed using two commonly used kinetic models, which were pseudo-first-order and pseudosecond-order kinetic models. Their expressions are given in eqn (3) and (4),

$$
\begin{gathered}
\ln \left(Q_{1 \mathrm{e}}-Q_{t}\right)=\ln Q_{1 \mathrm{e}}-k_{1} t \\
\frac{t}{Q_{t}}=\frac{t}{Q_{2 \mathrm{e}}}+\frac{1}{k_{2} Q_{2 \mathrm{e}}{ }^{2}}
\end{gathered}
$$

where $Q_{1 \mathrm{e}}\left(\mathrm{mg} \mathrm{g}^{-1}\right)$ and $Q_{2 \mathrm{e}}\left(\mathrm{mg} \mathrm{g}^{-1}\right)$ are the calculated adsorption capacities at equilibrium, and $k_{1}\left(\mathrm{~min}^{-1}\right)$ and $k_{2}(\mathrm{~g}$ $\mathrm{mg}^{-1} \min ^{-1}$ ) denote the rate constants of pseudo-first-order and pseudo-second-order kinetic models, respectively.

All the kinetic parameters for the adsorption of $\mathrm{Cu}^{2+}, \mathrm{Pb}^{2+}$, $\mathrm{Cr}^{3+}$ and $\mathrm{Zn}^{2+}$ are shown in Table 1. The results display that all the correlation coefficients $R^{2}$ are greater than 0.9966. In
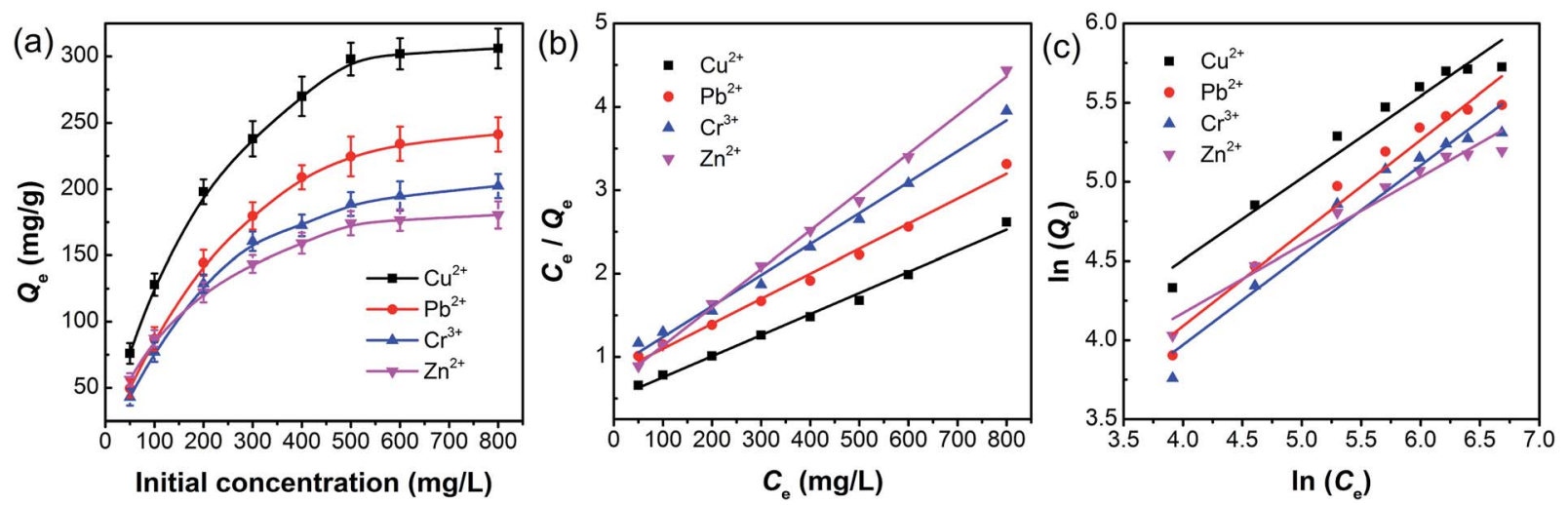

Fig. 9 (a) The effect of the initial concentration on the equilibrium adsorption capacity for $\mathrm{Cu}^{2+}, \mathrm{Pb}^{2+}, \mathrm{Cr}^{3+}$ and $\mathrm{Zn}^{2+}$. The (b) $\mathrm{Langmuir}^{2}$ and (c) Freundlich isotherm models for the absorption of $\mathrm{Cu}^{2+}, \mathrm{Pb}^{2+}, \mathrm{Cr}^{3+}$ and $\mathrm{Zn}^{2+}$ by pAHA-cellulose (adsorption conditions: $30^{\circ} \mathrm{C}, 120 \mathrm{~min}$ and initial $\mathrm{pH}$ values). 
Table 2 The Langmuir and Freundlich parameters obtained for the adsorption of $\mathrm{Cu}^{2+}, \mathrm{Pb}^{2+}, \mathrm{Cr}^{3+}$ and $\mathrm{Zn}^{2+}$ by pAHA-cellulose

\begin{tabular}{|c|c|c|c|c|c|c|c|}
\hline $\mathrm{Pb}^{2+}$ & 333.3 & 0.0038 & 0.9905 & $0.2475-0.8403$ & 5.6983 & 1.7029 & 0.9560 \\
\hline $\mathrm{Cr}^{3+}$ & 268.8 & 0.0043 & 0.9906 & $0.2252-0.8230$ & 5.5023 & 1.7660 & 0.9397 \\
\hline $\mathrm{Zn}^{2+}$ & 216.9 & 0.0069 & 0.9974 & $0.1534-0.7435$ & 11.6411 & 2.3295 & 0.9584 \\
\hline
\end{tabular}

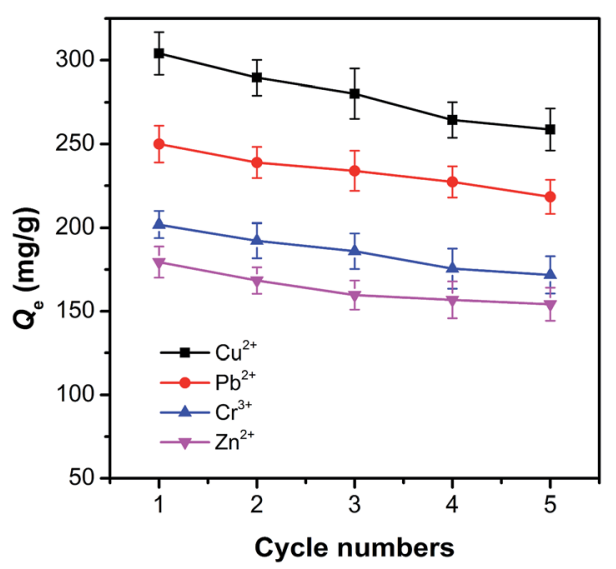

Fig. 10 The adsorption capacities of pAHA-cellulose at different cycle numbers.

addition, the calculated values $Q_{2 \mathrm{e}}$ obtained from the pseudosecond-order model are closer to the experimental values $Q_{\exp }$, indicating the pseudo-second-order model can more accurately capture the adsorption kinetics.

\section{Adsorption isotherms}

In order to investigate the adsorption ability of pAHA-cellulose, adsorption experiments were executed at different initial concentrations. As shown in Fig. 9a, the equilibrium adsorption amounts increase upon increasing the initial concentration of metal ions, which can be attributed to the increasing driving force produced by the concentration gradient. ${ }^{\mathbf{4 1 , 4 2}}$

In order to describe the interactive behavior between the metal ions and adsorbent, the equilibrium adsorption isotherm models were studied to establish reliable predictive modelling of the adsorption systems. Herein, the Langmuir and Freundlich isotherms are analyzed to investigate the adsorption process. The Langmuir isotherm model assumes that the adsorption occurs at specific homogeneous sites in the adsorbent and with monolayer coverage of the adsorbent surface. The Langmuir equation is expressed by eqn (5),

$$
\frac{C_{\mathrm{e}}}{Q_{\mathrm{e}}}=\frac{C_{\mathrm{e}}}{Q_{\max }}+\frac{1}{k_{\mathrm{L}} Q_{\max }}
$$

where $Q_{\mathrm{e}}\left(\mathrm{mg} \mathrm{g}^{-1}\right)$ and $Q_{\max }\left(\mathrm{mg} \mathrm{g}^{-1}\right)$ are the equilibrium and maximum adsorption capacities per unit mass of pAHAcellulose, respectively. $C_{\mathrm{e}}\left(\mathrm{mg} \mathrm{L}^{-1}\right)$ denotes the adsorbate concentration at equilibrium. $k_{\mathrm{L}}\left(\mathrm{L} \mathrm{mg}{ }^{-1}\right)$ is the Langmuir equilibrium constant related to the energy of the adsorption process. Furthermore, the equilibrium parameter, a dimensionless constant $R_{\mathrm{L}}$, is an essential characteristic of the Langmuir isotherm and can be expressed using eqn (6),

$$
R_{\mathrm{L}}=\frac{1}{1+k_{\mathrm{L}} C_{\mathrm{o}}}
$$

where $R_{\mathrm{L}}$ denotes the isotherm type is favorable $\left(0<R_{\mathrm{L}}<1\right)$, unfavorable $\left(R_{\mathrm{L}}>1\right)$, linear $\left(R_{\mathrm{L}}=1\right)$ or irreversible $\left(R_{\mathrm{L}}=0\right)$. As shown in Table 2 , all the $R_{\mathrm{L}}$ values fall between 0 and 1 , indicating a favorable adsorption.

The Freundlich isotherm, an empirical model, assumes a heterogeneous surface with a non-uniform distribution of adsorption heat over the surface. The model can be expressed by eqn (7).

$$
\ln Q_{\mathrm{e}}=\ln k_{\mathrm{F}}+\frac{1}{n} \ln C_{\mathrm{e}}
$$

where $k_{\mathrm{F}}$ and $n$ represent the Freundlich constant and heterogeneity factor calculated from the intercept and slope of the linear equation, respectively.

All the isotherm parameters are listed in Table 2, which reflects that the Langmuir isotherm can fit the experimental data well with a higher $R^{2}$ value $(>0.99)$, favorable $R_{\mathrm{L}}(0.1534-$ $0.7435)$ and reasonable Langmuir constant $\left(k_{\mathrm{L}}>0\right)$. When compared with the representative studies on the adsorbents containing amidoxime and/or hydroxamic acid functional groups (Table S1, ESI $\dagger$ ), ${ }^{17,32,35,36,43-46}$ pAHA-cellulose shows an increased adsorption capacity for almost all the metal ions studied. This improved adsorption ability can be due to the coexistence of the amidoxime and hydroxamic acid functional groups, confirming the possible chelation mechanism.

\section{Regeneration of pAHA-cellulose}

The regeneration ability is an essential parameter for potential practical application and further analysis of the mechanism of the sorption between the adsorbent and adsorbate. ${ }^{42}$ The reusability of pAHA-cellulose was investigated by operating the adsorption-desorption process for five consecutive cycles and the adsorption amount at each cycle detected. As displayed in Fig. 10, the equilibrium adsorption capacities for all the metal ions studied can still retain above $86 \%$ of their initial amounts in the $5^{\text {th }}$ regeneration cycle. Thus, the pAHA-cellulose adsorbent can be recycled almost without any obvious loss in the adsorption capacity, demonstrating a benign renewable adsorbent. 


\section{Conclusions}

A new chelating cellulosic adsorbent bearing amidoxime and hydroxamic acid groups (pAHA-cellulose) was synthesized via a free-radical initiation method using EMCA as a monomer. After modification, the pAHA-cellulose shows a coarse microscopic structure with partial destruction of its crystallinity. The batch adsorption data indicates the excellent and rapid removal of pAHA-cellulose towards heavy metal ions from an aqueous system. The uptake of pAHA-cellulose for $\mathrm{Cu}^{2+}, \mathrm{Pb}^{2+}, \mathrm{Cr}^{3+}$ and $\mathrm{Zn}^{2+}$ was $\mathrm{pH}$-dependent and the adsorption obeys the pseudosecond-order kinetic model. According to the isotherm study, the Langmuir isotherm can reasonably capture the adsorption process, indicating the monolayer coverage of metal ions on the homogeneous surface of pAHA-cellulose. After five cycles of adsorption-desorption, the pAHA-cellulose can retain over $86 \%$ of its adsorption ability for all the metal ions studied, demonstrating an efficient and benign renewable candidate for metal ions removal from aqueous systems.

\section{Acknowledgements}

This work was supported by the National Natural Science Foundation of China (No. 51403141), the Graduate Student Innovation Project of Jiangsu Province (No. KYLX16_0134) and the Natural Science Foundation of Jiangsu Province (No. BK20140347).

\section{Notes and references}

1 X. Liu, W. Gong, J. Luo, C. Zou, Y. Yang and S. Yang, Appl. Surf. Sci., 2016, 362, 517-524.

2 C. Duan, N. Zhao, X. Yu, X. Zhang and J. Xu, Cellulose, 2013, 20, 849-860.

3 F. Fu and Q. Wang, J. Environ. Manage., 2011, 92, 407-418.

4 L. Zhao and H. Mitomo, J. Appl. Polym. Sci., 2008, 110, 13881395.

5 R. Akkaya and U. Ulusoy, J. Hazard. Mater., 2008, 151, 380388.

6 İ. Duru, D. Ege and A. R. Kamali, J. Mater. Sci., 2016, 51, 6097-6116.

7 Saepurahman, G. P. Singaravel and R. Hashaikeh, J. Mater. Sci., 2015, 51, 1133-1141.

8 M. Visa and A.-M. Chelaru, Appl. Surf. Sci., 2014, 303, 14-22.

9 T.-D. Nguyen-Phan, V. H. Pham, E. J. Kim, E.-S. Oh, S. H. Hur, J. S. Chung, B. Lee and E. W. Shin, Appl. Surf. Sci., 2012, 258, 4551-4557.

10 Z. Li, W. Kang, N. Wei, J. Qiu, C. Sun and B. Cheng, RSC Adv., 2017, 7, 8220-8229.

11 A. M. Nada, M. Y. Alkady and H. M. Fekry, BioResources, 2008, 3, 46-59.

12 H. Sokker, A. Ghaffar and A. Nada, J. Appl. Polym. Sci., 2006, 100, 3589-3595.

13 A. M. A. Nada and N. A. El-Wakil, J. Appl. Polym. Sci., 2006, 102, 303-311.

14 X. Zhang, H. Yu, H. Yang, Y. Wan, H. Hu, Z. Zhai and J. Qin, J. Colloid Interface Sci., 2015, 437, 277-282.
15 J. Xiong, C. Jiao, C. Li, D. Zhang, H. Lin and Y. Chen, Cellulose, 2014, 21, 3073-3087.

16 A. Fukuoka and P. L. Dhepe, Angew. Chem., 2006, 45, 51615163.

17 M. L. Rahman, N. Rohani, N. Mustapa and M. M. Yusoff, J. Appl. Polym. Sci., 2014, 131, 40833.

18 M. J. Zohuriaan-Mehr, A. Pourjavadi and M. Salehi-Rad, React. Funct. Polym., 2004, 61, 23-31.

19 A. Dessouki, M. El-Tahawy, H. El-Boohy, S. El-Mongy and S. Badawy, Radiat. Phys. Chem., 1999, 54, 627-635.

20 Z. Karim, M. Hakalahti, T. Tammelin and A. P. Mathew, RSC Adv., 2017, 7, 5232-5241.

21 S. Ș. Bașarır and N. P. Bayramgil, Cellulose, 2012, 20, 827839.

22 M. J. Haron, M. Tiansih, N. A. Ibrahim, A. Kassim and W. M. Z. W. Yunus, BioResources, 2009, 4, 1305-1318.

23 A. Nilchi, A. A. Babalou, R. Rafiee and H. Sid Kalal, React. Funct. Polym., 2008, 68, 1665-1670.

24 W.-l. Zheng, W.-l. Hu, S.-y. Chen, Y. Zheng, B.-h. Zhou and H.-p. Wang, Chin. J. Polym. Sci., 2014, 32, 169-176.

25 W. Li, R. Liu, H. Kang, Y. Sun, F. Dong and Y. Huang, Polym. Chem., 2013, 4, 2556.

26 L. Zhang, J. Luo, T. J. Menkhaus, H. Varadaraju, Y. Sun and H. Fong, J. Membr. Sci., 2011, 369, 499-505.

27 C. Liu, P.-C. Hsu, J. Xie, J. Zhao, T. Wu, H. Wang, W. Liu, J. Zhang, S. Chu and Y. Cui, Nat. Energy, 2017, 2, 17007.

28 D. Saraydin, Y. Isikver and N. Sahiner, Polym. Bull., 2001, 47, 81-89.

29 G. A. Skarja, A. L. Brown, R. K. Ho, M. H. May and M. V. Sefton, Biomaterials, 2009, 30, 1890-1897.

30 N. A. Ibrahim, F. Abu-Ilaiwi, M. Z. A. Rahman, M. B. Ahmad, K. Z. M. Dahlan and W. M. Z. W. Yunus, J. Polym. Res., 2005, 12, 173-179.

31 D. Muri, J. W. Bode and E. M. Carreira, Org. Lett., 2000, 2, 539-541.

32 M. L. Rahman, S. M. Sarkar, M. M. Yusoff, A. K. D. Kulkarni, Z. Z. Chowdhury and M. E. Ali, BioResources, 2016, 11, 67806800.

33 R. Saliba, H. Gauthier, R. Gauthier and M. Petit-Ramel, J. Appl. Polym. Sci., 2000, 75, 1624-1631.

34 Y. Xie, J. Wang, M. Wang and X. Ge, J. Hazard. Mater., 2015, 297, 66-73.

35 K. Saeed, S. Haider, T.-J. Oh and S.-Y. Park, J. Membr. Sci., 2008, 322, 400-405.

36 S. S. Yong Wen, M. L. Rahman, S. E. Arshad, N. L. Surugau and B. Musta, J. Appl. Polym. Sci., 2011, 35449, 4443-4451.

37 K. Hltoshl and S. Yasumlchl, J. Appl. Polym. Sci., 1995, 56, 147-151.

38 Y. Zhang, X. Li, H. Li, M. E. Gibril, K. Han and M. Yu, RSC Adv., 2013, 3, 11732.

39 F. A. Alakhras, K. A. Dari and M. S. Mubarak, J. Appl. Polym. Sci., 2005, 97, 691-696.

40 M. Lutfor, S. Sidik, W. Wan Yunus, M. Rahman, A. Mansor and M. Haron, J. Appl. Polym. Sci., 2001, 79, 1256-1264.

41 J. Tao, J. Xiong, C. Jiao, D. Zhang, H. Lin and Y. Chen, ACS Sustainable Chem. Eng., 2016, 4, 60-68. 
42 L. Wang, J. Zhang, R. Zhao, Y. Li, C. Li and C. Zhang, Bioresour. Technol., 2010, 101, 5808-5814.

43 M. Lutfor, S. Silong, W. M. Zin, M. Ab Rahman, M. Ahmad and J. Haron, Eur. Polym. J., 2000, 36, 2105-2113.

44 M. R. Lutfor, S. Sidik, W. Wan Yunus, M. Rahman, A. Mansor and M. Haron, J. Appl. Polym. Sci., 2001, 79, 1256-1264.
45 A. S. El-Khouly, Y. Takahashi, A. A. Saafan, E. Kenawy and Y. A. Hafiz, J. Appl. Polym. Sci., 2011, 120, 866-873.

46 Y. Xie, J. Wang, M. Wang and X. Ge, J. Hazard. Mater., 2015, 297, 66-73. 